\title{
João Guimarães Rosa, um filossemita? A questão judaica, as cartas e o testemunho de Israel Klabin
}

\author{
Jacques Fux ${ }^{*}$
}

\begin{abstract}
Resumo
Este artigo tem como objetivo mostrar as relações que João Guimarães Rosa travou com a família judaica de Israel Klabin. A partir das correspondências entre Rosa e Klabin e de uma entrevista realizada por mim, intento demonstrar o filossemitismo de Rosa. Além disso, com base em documentos, livros e pesquisas, discuto o conhecimento e a atuação de Rosa na emissão de vistos para judeus durante seu período na Embaixada Brasileira em Hamburgo.
\end{abstract}

\section{Palavras-chave}

Rosa. Nazismo. Testemunho. Filossemitismo. Antissemitismo.

\section{Introdução}

Uma das grandes questões que ainda não se tem resposta definitiva é a participação ou não de João Guimarães Rosa na emissão de vistos a judeus durante sua época na Embaixada Brasileira em Hamburgo. Muitos artigos, estudos e livros já foram escritos, porém sem nenhuma resposta conclusiva. Este artigo pretende fazer um apanhado de todos os estudos realizados nessa área, além de agregar mais um fato inédito: o testemunho de Israel Klabin, empresário judeu brasileiro, que teve a oportunidade de conviver e se corresponder com Guimarães Rosa.

Assim começa uma das correspondências entre Rosa e Klabin: "Meu caro Klabin - queria dizer a Você que me alegrou a sua bela carta, estuante de inconformismo e de vontade-de-ação, e que trouxe a êste seu amigo mais velho (e já sincero admirador) muita generosidade, envolta em afetuosa confiança. Obrigado" (ROSA,

\footnotetext{
Pós-doutorando em Teoria Literária - Unicamp. Doutor em Literatura Comparada pela Universidade Federal de Minas Gerais (UFMG) e pela Université Charles-de-Gaulle- Lille 3. Agradeço ao CNPq pela bolsa de pós-doutorado júnior e ao Márcio Seligmann-Silva pela supervisão. E-mail: jacfux@gmail.com. Agradeço também a colaboração e o carinho de Israel Klabin, Nathan Klabin, Stela Klabin e Débora Wainstock.
} 
1949a). "João Guimarães Rosa: [...] Sua presença em mim se prende essencialmente aos seguintes fatos: [...] c) Sua presença ao meu lado, circunspecto e curioso, na cadeira que era de meu pai na sinagoga. Era uma noite de Kol-Nidrei, véspera do dia da expiação" (KLABIN, 1963). Essas correspondências atestam a próxima relação de Guimarães Rosa com Israel Klabin. A primeira carta datada "Paris, 4.VI.49" mostra um Rosa com seus 41 anos admirando um jovem e promissor escritor, Israel Klabin, então com seus 23 anos, cheio de sonhos e vontade-de-ação. Já na carta endereçada à Guimarães Rosa "Rio de Janeiro, 30 de agôsto de 1963", Klabin lembra com saudade e nostalgia a presença de Rosa, na noite mais importante do calendário judaico (Yom Kipur), sentado na cadeira de seu pai ${ }^{1}$, e o olhar atento de Rosa durante a primeira noite do dia da expiação.

A partir dessa pouca, mas profunda relação com Rosa, de suas lembranças pessoais e do seu testemunho que no dia 30 de Maio de 2011 Israel Klabin concedeume uma longa e saborosa entrevista. Nessa entrevista e neste artigo busco mostrar indícios da íntima relação de Rosa com a família de Klabin (e de Haas). Mostrar o carinho que Rosa sentia por uma família judia, e vice-versa, pode ajudar a preencher algumas lacunas (ou agregar algumas pequenas e novas informações) acerca do seu período em Hamburgo e sua vontade de agir em favor dos judeus. Muitos autores sugerem, mas não confirmam, a participação efetiva de Rosa na emissão de vistos a judeus para fugirem da perseguição nazista. Aqui apresento esses estudos permeados pela entrevista com Israel Klabin.

Israel Klabin ${ }^{2}$, fundador e atual presidente da Fundação Brasileira de Desenvolvimento Sustentável, nasceu em 1926 no Rio de Janeiro. É um dos três filhos de Wolf Klabin, patriarca da família, que foi casado com a filha de Arthur Haas. Até seus 30 anos Israel Klabin foi um acadêmico (segundo ele próprio). Estudou engenharia, fez mestrado em matemática e física e fez o curso de Maître de Conférence na SciencesPo, em Paris. Escrevia suas poesias, viajava bastante, não se envolvia em causas políticas e nem com o sionismo até que em 1957 seu pai faleceu, tornando-o responsável pelos negócios da família. Ex-prefeito do Rio de Janeiro (19791980), deixou de lado a sua veia literária para se dedicar inteiramente à suas empresas e ao desenvolvimento sustentável do país.

Oriundo de uma família mais conservadora judaica, Klabin, inicialmente, não se interessava muito pela parte religiosa do judaísmo. Sua casa, entretanto, era frequentada por personalidades sionistas muito importantes como Golda Meir, Ben Gurion e Menachem Begin. Ao longo de sua vida, Klabin foi se aproximando mais da religião judaica e sempre esteve próximo e ligado às questões sionistas e a fundação do Estado de Israel como pode ser verificado nas passagens abaixo:

\footnotetext{
${ }^{1}$ Os fundadores ou os grandes contribuintes têm uma cadeira cativa na sinagoga, muitas vezes com o seu nome escrito, como é o caso de Wolf Klabin. É uma enorme honra sentar na cadeira de outra pessoa, já que, mesmo que não estejam lá, ninguém pode ocupá-las.

2 Em 2011, a Editora Elsevier publicou uma biografia de Israel Klabin: Israel Klabin: a urgência do presente. Com prefácio de Fernando Henrique Cardoso.
} 
O que eu me formei lá na SciencesPo foi Maître de Conférence, tinha o Maître de Conférence e o Maître de Administration. O Maître de Conférence era humanismo. [...] O meu envolvimento com o judaísmo, vamos chamar assim, o meu envolvimento político, foi uma coisa que foi crescendo cada vez mais, depois da morte do meu pai e depois que fui chamado pelo Ben Gurion para ir para Israel. Enquanto isso eu era judeu porque fiz Bar-Mitzvá, minha família era muito judia (KLABIN, 2011a).

A partir de 1952, cerca de 1500 famílias judias emigraram do Egito para o Brasil, número que pode ser considerado 'massivo', no conjunto da população judaica brasileira, pois nunca tão grande número de judeus, em curto espaço de tempo, havia emigrado ao Brasil. No período, o chefe do Departamento de Imigração do Ministério da Justiça brasileira, ao ser consultado sobre a admissão dos refugiados judeus do Oriente Médio, de forma surpreendente, exigiu, para cada visto de entrada, 'valor em dólares, por cabeça'. Israel Klabin, industrial judeu no Rio de Janeiro, quando soube do fato, aconselhado pelo intelectual Augusto Frederico Schmidt, procurou o presidente Juscelino Kubitschek, que liberou a entrada dos judeus-egípcios e substituiu o funcionário (MIZRAHI, 2003, p. 189).

A relação de Klabin com Guimarães Rosa se deu por intermédio de seu tio, Edmundo Haas. Rosa, ao ingressar na Faculdade de Medicina, conheceu Edmundo, então colega de classe, com quem travou grande amizade. Em sua carta de "Paris, 4.VI.49." Rosa pergunta por Edmundo: "Como vai o Edmundo? Quando vem ele até cá? Quando volta Você também à Europa? Que é que vocês querem, de Paris" (ROSA, 1949b). Assim Israel Klabin, ainda jovem estudante em Paris, foi ciceroneado por Rosa como mostrado na entrevista e também nas memórias presentes na carta de 1963.

Guimarães foi colega de turma de medicina do meu Tio Edmundo. Ele veio de Cordisburgo para estudar medicina e ficou praticamente morando na casa de meu avô, Arthur, e estabeleceu uma relação muito profunda com toda família. Tanto que quando eu fui para França a minha mãe e o Edmundo, que era o colega dele, pediram para ele'overlook', para ele me direcionar (KLABIN, 2011a).

Carinhosa recepção e acolhida quase injustificada a um jovem esganiçado e sedento estudante, em Paris. Entre as memórias desta hospedagem revejo: lulas num restaurante tunisiano e uma conversa quase descoberta sobre salvação e anatomia (KLABIN, 1963).

\section{O concurso de ingresso ao Itamaraty e a família Haas}

Aos 26 anos de idade o então médico João Guimarães Rosa escreve a sua mãe relatando a aprovação, em segundo lugar, no exame do Itamaraty. Rosa explica que ficara "estonteado com o ambiente barulhento do Rio de Janeiro, e com o luxo magnificente do Itamaraty" (RICUPERO, 2006, p. 66). Já numa carta datada do dia 6 de julho de 1934 relata a dificuldade da prova: "De 57 (candidatos), só 10 foram habilitados [...] Desses 10, talvez seja eu o único que não esteve ainda na Europa; além disso, posso garantir que esse Concurso é o mais difícil que se processa no Brasil [...] Assim, estou satisfeitíssimo, adquiri mais confiança em mim mesmo, e espanei os brasões" (RICUPERO, 2006, p. 67).

Rosa ainda não tinha morado na Europa. Não tinha vivido fora do país. Havia nessa declaração (segundo Ricupero) talvez um ressentimento por ainda não ter vivido em outros lugares, um viator ainda sem viagens ao exterior. Porém, seu saber e sua cultura eram enormes. Em sua prova de Francês, foi the perguntado sobre o que 
conhecia de Literatura Clássica Francesa e sua resposta foi categórica: "Toda". "O examinador admirado de audácia tamanha, sorriu e quis saber: 'Desde quando o senhor lê Francês? "' (GUIMARAES, 2006, p. 97). Segundo o próprio Rosa, ele começara a ler os clássicos com nove anos de idade. Outras provas foram realizadas e o desempenho de Rosa foi brilhante.

Além do grande saber teórico sobre a França e sua Literatura, teria tido Rosa alguma outra influência marcante e determinante? Segundo o relato de Israel Klabin, sim, de acordo com a transcrição abaixo:

Meu avô era um francês. Era um enraizado na cultura francesa. E nessas conversas o Guimarães aprendeu tudo sobre Paris. O meu avô tinha em cima da escrivaninha dele duas coisas: o busto de Napoleão. Ele olhava para aquele busto e falava, assim, tradição da família: que o Napoleão era judeu. [...] O meu avô sabia tudo de Paris. Tanto que quando ele veio fazer o exame do Itamaraty caiu exatamente que ele fizesse, que ele falasse sobre Paris, não sei direito, ou qualquer coisa ligada a isso. Não sei exatamente o que foi. E ele fez uma descrição tanto em francês, ele falava francês com meu avô, ele aprendeu francês na casa do meu avô. Tanto isso quanto as ruas de Paris. Sabia tudo de Paris. Meu avô vivia em Belo Horizonte, mas a alma dele estava em Paris. [...] A história da família era Paris. E aí ele (Rosa) fez um sucesso. Até perguntaram a ele se ele tinha morado na França, aí ele disse não, eu morei foi em Belo Horizonte. E foi lá que eu aprendi sobre a cultura francesa. [...] O Arthur Haas era um nobre francês. Era um aristocrata francês. Rico que veio para financiar a fundação de Belo Horizonte. E acabou se apaixonando e ficou lá. Foi na França, pegou a família e voltou pra lá. Arthur Haas era um judeu confesso (KLABIN, 2011a).

Wolf Klabin, pai e patriarca da família de Israel Klabin, foi casado com a filha de Arthur Haas, empresário francês cuja casa era frequentada por Guimarães Rosa, como mostrado na entrevista acima. $O$ pai de Haas tinha sido intendente do exército francês na revolução napoleônica. Francês de nascimento, com a anexação de sua cidade à Alemanha, Haas tentou se radicar na Rússia. Acabou vindo para o Brasil onde ajudou na construção de Belo Horizonte e sempre manteve relações com as lideranças judaicas no mundo. Em Vidas que sangram história: a comunidade judaica de Belo Horizonte, Renato Pfeffer, ao relatar a criação da comunidade judaica de Belo Horizonte, escreve: "Até 1910, o único judeu com a presença constatada em Belo Horizonte é Arthur Haas. Acredita-se que os demais judeus que aqui passaram não fixaram residência. As primeiras famílias que aqui se fixaram o fizeram no início da década de 1910" (PFEFFER, 2003, p. 62).

Na carta endereçada Guimarães Rosa, data de 30 de Agosto de 1963, Klabin ainda rememora alguns fatos:

Sua presença em mim se prende essencialmente aos seguintes fatos: a) memórias de ouvir falar, do avô aos tios e minha mãe - Ele quando rapaz sem sair de Belo Horizonte conhecia todas ruas de Paris e falava alemão. Alemão, esse impossível mar de palavras, verbos cachoeirentos e exdruxolozidades sintáticas - ... Que gênio! (KLABIN, 2011a).

Rosa, de fato, conhecia muitas línguas. Em uma entrevista concedida à sua prima do Curvelo, de acordo com Vicente Guimarães, assim se expressou: 
Falo: português, alemão, francês, inglês, espanhol, italiano, esperanto, um pouco de russo; leio: sueco, holandês, latim, e grego (mas com dicionário agarrado); entendo alguns dialetos alemães; estudei a gramática: do húngaro, do árabe, do sânscrito, do lituânio, do polonês, do tupi, do hebraico, do japonês, do tcheco, do finlandês, do dinamarquês; bisbilhotei um pouco a respeito de outras. Mas tudo mal. Eu acho que estudar o espírito e o mecanismo das outras línguas ajuda muito a compreensão mais profunda do idioma nacional. Principalmente, porém, estudando-se por divertimento, gosto e distração (GUIMARAES, 2006, p. 54)

Assim seria surpreendente, mais não impossível, que a afirmação de Klabin fosse verdadeira em relação ao conhecimento de Rosa de "todas as ruas de Paris".

Em relação à literatura de Klabin, Rosa, em suas cartas, cita bastante alguns trechos do jovem e promissor poeta. Essas cartas escritas em Paris (Ambassade du Brésil), em "4.VI.49" e em "11.VII.49" mostram um Guimarães Rosa muito interessado pelas "letras" de Klabin. Assim escreve Rosa em sua primeira carta: "Mas, e os escritos, que me prometeu mandar?! Os contos, poemas, estudos, as 'miuçalhas'? Estou esperando, interessadíssimo. Apesar de ter sido tão curto e apressado o nosso contacto aqui em Paris, é com a mais rigorosa sinceridade que reafirmo esperar muito de Você, nas letras brasileiras" (ROSA, 1949a). Já na segunda carta, Rosa cita diversos versos de poemas de Klabin, do livro Poemata, que 'publicado ${ }^{3 /}$ em 1950 pela Editora Bloch. Assim escrever Rosa:

\begin{abstract}
Agradeço muito a Você a remessa das poesias e do conto. Esperava-os com impaciência, li-os com o maior prazer, e tenho-os relido com estima crescente. Acho que valem ainda mais do que eu imaginava, e Você pode acreditar na sinceridade limpa com que afirmo. Estou certo de que, mesmo se Você não escrevesse nada mais, bastavam essas poesias para colocar seu nome entre os dos nossos bons poetas. Entre as mais autênticas. Porque a verdade de sua expansão é profunda, sob marca de fatalidade. Fico pensando que Você se expressa poeticamente não apenas por uma necessidade de dar forma às fórmulas e forças que indesejadamente capta ou produz, mas mesmo pela ânsia de libertar-se de tal necessidade. Você, de cada vez, larga sua poesia, a ver se fica para sempre livre desse íntimo incômodo, se, com esse esforço, a esse preço, consegue 'secar a fonte'. Seus poemas, sinto-os como 'canais de drenagem', não de 'irrigação'. São, na forma e no sentido, poesia legítima - densa que, por si mesma, se impõe ao poeta, a partir do ponto em que a prosa não bastaria para dizer o que tem de ser dito, como um avião não pode deixar de desligar-se do chão e subir no ar, uma vez chegada à borda da esplanada (ROSA, 1949b).
\end{abstract}

Questionado sobre os seus versos, sua literatura e do apreço que Rosa atribui aos seus poemas, Klabin se mostra modesto:

Fux: Aqui, nessas cartas, o Guimarães Rosa elogia muito suas poesias.

Klabin: Isso era sacanagem dele. Era a amizade que ele tinha pela família.

Fux: Porque aqui (nas cartas) têm coisas muito interessantes.

Klabin: Eu tenho autocrítica suficiente para saber que era de segunda ordem. Aquela época era uma época muito hormonal. Ele era amicíssimo meu, ele gostava muito de mim. Eu me lembro quando foi já mais tarde, eu já estava até separado da Lina, mas eu ia visitá-lo quando estava aqui. Ele tinha o escritório dele no

\footnotetext{
${ }^{3}$ Publicação particular.
} 
Palácio do Itamaraty, aquela entrada do lado, era o departamento de Geografia ${ }^{4}$, era um buraco que jogaram ele lá, porque, sei lá, talvez o pessoal não gostava dele, não sei, naquela época. Eu fui visitá-lo lá depois de 64. E ele estava lá naquele buraco dele lá. E a gente assentava lá e ficava conversando, conversando sobre um monte de coisas (KLABIN, 2011a).

Outras lembranças de Klabin ainda podem ser encontradas na carta de 1963: "o seu escritório no Itamaraty. Mapas, alfarrábio, levantamentos aerofotogramétricos. Alquimia ou geografia ?" (KLABIN, 1963). Já Rosa, em sua carta do dia "17.VII.49", cita e comenta vários trechos dos poemas de Klabin. Essas passagens podem ser encontradas no livro Poemata. Mesmo com essa amizade e proximidade, as palavras de Rosa são calorosas e os elogios são grandes, sinceros e apresenta um Klabin verdadeiramente poeta.

\begin{abstract}
Mas, dessa poesia, deixe-me brincar de achar a chave. O poeta $\mathrm{K}$. é tentado, é abrigado, inicialmente, não a apoderar-se do mundo, mas a descobrir, na agitação do mundo, um qualquer ponto de apoio, se não um sistema de leis, dissimulado no caótico. Assim, o poeta K. se angustia: I) por querer ser, ou ver-se obrigado a ser um centro consciente ('o monstro sapiens foge de casa'/ 'olhamos medrosos o interior das velhas questões'/ 'e sem mais reis... e sem mais deuses'/ 'entramos, monstros em estranha estrada, ladeada...'. [...] Perdoe-me. Não estou cortando aos pedacinhos seus belos poemas, para reconstruí-los, arbitrariamente, como uma invenção de 'puzzle'. (Vê bem que as constantes existem neles, e também que, no fluxo da criação poética, não haja lógica de sucessão, mas simultaneidade, transposições involuntárias, anteposição e instantâneos 'anacronismos'). Não estou analisando. Não estou fazendo ludismo. Obedeci, apenas, a uma sugestão, de momento, que seus versos me transmitiram. Poder sugerir, com força, não será o mais importante para o poema? (ROSA, 1949b).
\end{abstract}

Talvez o que tenha levado Rosa a apreciar tanto os versos do poeta $K$. tenha sido, além da amizade, o grande o gosto pela literatura francesa:

Fux: E o que o Senhor lia?

Klabin: Sobretudo literatura francesa. [...] Minha vida era muito focada em erudição literária, música, um viciado (KLABIN, 2011a).

A entrevista com Israel Klabin transcorreu bem. Além de suas relações com Guimarães Rosa, que descreveu com detalhes, como mostrado nas partes transcritas, Klabin falou sobre seus tempos de juventude, seu amor pela literatura (que ainda preserva), suas andanças pelo mundo. Comentou, também, acerca de sua próxima relação com o sionismo e a participação em algumas atividades em favor do Estado de Israel. Nessa primeira parte tentei inserir pequenos pontos convergentes entre as lembranças de Klabin e a vida, já bastante estudada, de Rosa.

\footnotetext{
${ }^{4} \mathrm{Na}$ verdade Rosa, promovido a embaixador, não chefiou embaixada nenhuma. Preferiu, apesar de insistentes convites, a permanecer no cargo de Chefe do Serviço de Demarcação de Fronteiras.

${ }^{5} \mathrm{Na}$ Revista de Estudos Avançados 58, há um artigo que mostra a paixão de Rosa pela Geografia. "Guimarães Rosa e a Geografia".
} 


\title{
Aracy, Rosa e a questão judaica
}

Muitos livros simplesmente dizem que Guimarães Rosa emitiu vistos para que judeus não fossem mortos durante a $2^{a}$ Guerra Mundial, mas somente Aracy de Carvalho Guimarães Rosa e Luis Martins Souza Dantas possuem o título de Justo entre as Nações ${ }^{6}$. Qual teria sido, de fato, a participação de Rosa? É muito perigoso ser genérico ao relatar um acontecimento de tamanha grandeza como fez, por exemplo, Vicente Guimarães ao dizer: "apoiado por sua mulher, Aracy, Rosa decidiu ajudar os judeus que o procuraram a escapar do país, para não serem mortos pelo regime nazista. Para isso, emitia passaportes sem a letra J que os identificaria, dando vistos de entrada para o Brasil" (GUIMARAES, 2006, p. 176). Isso não está correto, já que foi Aracy que comprovadamente ajudou os judeus (como será discutido). Rosa não tinha autonomia para dar vistos e nem emitir passaportes, como mostraremos ao longo do artigo. Moacyr Scliar também comete o mesmo preciosismo ao escrever, na introdução do livro Joãozito: a infância de João Guimarães Rosa que o "cônsul-adjunto em Hamburgo (Rosa) durante a época do nazismo, salvou muitos refugiados judeus, concedendo-Ihes vistos para o Brasil" (SCLIAR, 2006, p. 6). A Revista Bravo publicou uma reportagem em 2008 com trechos do Diário de Guerra de Guimarães Rosa. Acerca da concessão de vistos, Mariana Delfini escreve:

\begin{abstract}
A sua consternação com a perseguição originou a história de que Rosa teria ajudado judeus a fugir da Alemanha. Não há, contudo, documentos que comprovem esses atos. A historiadora Maria Luiza Tucci Carneiro, especialista em holocausto e professora da USP, procurou informações no Itamaraty e não encontrou nada. "Tenho a impressão de que ele tomou muito cuidado para não deixar rastros", diz Maria Luiza (DELFINI, 2008, p. 36).
\end{abstract}

Em seu livro O Brasil e a Questão Judaica, Jeffrey Lesser apresenta as controvertidas relações entre o governo brasileiro e os judeus. O que interessa aqui, sobretudo, é o período em que Guimarães Rosa, cônsul-adjunto de Hamburgo (19381942), viu e ouviu os terríveis relatos acerca da perseguição de judeus na Europa. "Em 1937, o Ministério das Relações Exteriores emitiu um Circular Secreta 1.127, autorizada pessoalmente por Getúlio Vargas. Essa circular proibia a emissão de vistos para pessoas de origem 'semítica', causando uma queda de $75 \%$ na imigração judaica durante $O$ ano seguinte. A rigorosa aplicação das poucas cláusulas que permitiam a entrada de judeus fez seu número diminuir ainda mais" (LESSER, 1995). Diante da Circular Secreta 1.127 e da troca de correspondência antissemita entre as embaixadas, como se portaram Rosa e Aracy?

Aracy Moebius de Carvalho Guimarães Rosa nasceu em Rio Negro, Paraná, em 1908 e faleceu em 2011. Poliglota, funcionária graduada do Consulado Brasileiro em Hamburgo, onde conheceu Rosa em 1938, é considerada um Justo entre as Nações pelo museu Yad Vashem (importante título recebido em 1982 para aqueles não judeus que arriscaram a vida para salvar judeus da Shoah), por ter ajudado judeus durante a perseguição nazista. Esse título só foi concedido, até hoje, a dois brasileiros: Aracy Moebius e Luiz Martins de Souza Dantas, também por sua ajuda aos judeus perseguidos na França, onde serviu como Embaixador do Brasil no início dos anos 40.

\footnotetext{
${ }^{6}$ Disponível em: http://www.arqshoah.com.br/galeria_justos.aspx. Acesso em 13/06/2011.
} 
Luiz Martins de Souza Dantas ainda é um desconhecido, apesar de comprovada sua participação efetiva na concessão de vistos a judeus. Justo entre as Nações ainda não foi descoberto pelo público acadêmico como Aracy. Segundo Avraham Milgram "Souza Dantas foi durante muito tempo ignorado pela literatura e continua desconhecido pelo público geral. [...] Suas atividades em favor dos judeus foram diametralmente opostas à política e ao tom no Itamaraty durante esse período (1922 - 1943)" (MILGRAM, 2007, p. 402). A participação tanto de Souza Dantas como a de Aracy é comprovada, já a participação de Rosa ainda resta um mistério. Assim continua Milgram: "Não só no serviço consular brasileiro da Alemanha ocorreram 'irregularidades' em matéria de vistos, o mesmo ocorria nos consulados da França. Com a diferença que na França era o embaixador quem fornecia os vistos aos judeus. Souza Dantas [...] agiu de forma excepcional em relação aos refugiados judeus concedendo-Ihes centenas de vistos diplomáticos, em sua grande maioria na segunda metade de 1940" (MILGRAM, 2007, p. 404). Um dado interessante e que podemos aproximar com Rosa é o fato de que a primeira mulher de Souza Dantas era judia e que ele tinha um grande amigo judeu, o que possivelmente influenciou sua ajuda efetiva na emissão de vistos e o seu filossemitismo (no caso de Rosa, a estreita ligação com a família Haas e Klabin). Assim escreve Milgram:

Souza Dantas estava perto dos 60 anos de idade quando se casou pela primeira vez com Aliza Meyer, judia norte-americana. Considerando que membros do Itamaraty casavam-se com mulheres que pertenciam por tradição, status e liames da classe política à aristocracia, o casamento de Souza Dantas com uma judia nos anos 1930 foi sem dúvida algo excepcional e anticonvencional. Além de sua recente esposa, havia na Embaixada que Souza Dantas depositava confiança, o veterano funcionário Levy, judeu naturalizado brasileiro, competente e falando corretamente o português. Segundo Luthero Vargas, a Embaixada 'é feita somente pelo Levy' (MILGRAM, 2007, p. 403).

O artigo de Milgram analisa bem a postura do Itamaraty frente a questão judaica além de revistar os trabalhos de Lesser e Tucci Carneiro. Milgram exalta, com razão, a participação de Souza Dantas, mas em nenhum momento fala da atuação de Rosa ou de Aracy (apenas sugere: "não só no serviço consular brasileiro da Alemanha ocorreram 'irregularidades' em matéria de vistos").

Dona Aracy, o anjo de Hamburgo, "embora o cargo ocupado não permitisse assinar documentos oficiais de concessão de visto, era responsável pelo contato com os requerentes" (JACOBSEN e VILELA, 2006). De acordo com a Concise Encyclopedia of the Holocaust, publicada pela International School for Holocaust Studies, Yad Vashem, Aracy começou a ajudar os judeus depois do progrom conhecido como Noite dos Cristais, ocorrido em 1938. Naquela fatídica noite, prenúncio da Shoah, nazistas na Alemanha e Áustria destruíram sinagogas, atacaram residências judaicas e mataram muitas pessoas. Sabendo da perseguição aos judeus e da necessidade de fugirem da Europa, Aracy fez o que julgava ser justo e correto. Segundo o relato de seu filho, Eduardo de Carvalho Tess: "minha mãe não achava aquilo justo, ignorou a determinação e, com a maior discrição, continuou a preparar os processos de vistos para judeus, à revelia de seus superiores" (TESS, 2008). Como não possuía o poder de emitir vistos sozinha, possivelmente contou com a cumplicidade (ou enganou) um 
funcionário da polícia de Hamburgo, que passou a emitir passaportes para judeus sem o " $\mathrm{J}$ " vermelho que os impedia de entrar no Brasil. "Depois, ela enfiava os vistos no meio da papelada que despachava com o cônsul-geral, que os assinava sem ver" (TESS, 2008).

Além de "enfiar os vistos no meio da papelada que despachava" Aracy ainda arriscou sua vida usando clandestinamente o carro do consulado para transportar judeus que se escondiam e, também, para distribuir alimentos aos judeus, desviando da cota que o consulado recebia. "Muitas vezes, ela transportou judeus no porta-malas do carro. Chegou a levar um deles no carro do consulado - me lembro que era um Opel Olympia alemão - para a Dinamarca" (TESS, 2008). Mesmo interpelada pela Gestapo, Aracy enfrentava os policiais: "minha mãe exibia muita segurança e autoridade; os alemães respeitavam a autoridade" (TESS, 2008). Além disso, alguns testemunhos de sobreviventes atestam a participação efetiva de Aracy como é o caso de Margareth Bertel Levy, que em 2006, gravou um depoimento ao historiador René Decol: "Aracy me levou pessoalmente ao navio, usando seu passaporte diplomático". No documentário Os nomes do Rosa de 1997, Margareth Levy aparece, também, dando seu testemunho em favor de Dona Aracy, responsável pela sua vida. De acordo com seu filho Eduardo Tess (que também aparece nesse mesmo documentário) "pelas informações que tenho, minha mãe deve ter salvo, no total, cerca de cem pessoas". Em 1983, ao receber a homenagem do Yad Vashem, Aracy disse: "Nunca tive medo", quem tinha medo era o Joãozinho. Ele dizia que eu exagerava, mas não se metia muito e me deixava ir fazendo" (Jornal do Tarde, 1968). Em Os nomes do Rosa Aracy, com 89 anos e visivelmente enferma, perguntada por Pedro Bial se ela tinha medo de fazer coisas ilegais para salvar judeus, responde com certa dificuldade -"não". -"E o Joãozinho", pergunta novamente Bial, -"não", responde Aracy. De acordo com o site ArqShoah, a declaração dada por Aracy acerca da participação de Rosa ao Jornal da Tarde é corroborada:

João Guimarães Rosa foi nomeado como cônsul-adjunto do Consulado em Hamburgo em 1938. Também desquitado, acabou se relacionando com Aracy. Segundo Aracy, em entrevista fornecida ao jornal Resenha Judaica em 1988, João sempre the dizia que qualquer dia ela iria desaparecer, tamanho risco que ela corria. Separados de antigos casamentos, viviam em casas diferentes, sendo ela quem abrigava os judeus em sua casa ${ }^{8}$.

Apesar do medo, de seu cansaço de esperança, segundo alguns estudiosos, Rosa estava era dando batalha. De acordo com a pesquisadora Ana Luiza Martins Costa "Guimarães Rosa e dona Aracy ajudaram muitos judeus a fugirem da Alemanha durante a guerra - pelo que foram, mais tarde homenageados" (COSTA, 2006, p. 18). E conforme Adriana Guimarães Jacobsen e Sônia B. M. Vilela:

\footnotetext{
7 Segundo Hanna Arendt "Nas condições do terror total, nem mesmo o medo pode aconselhar a conduta do cidadão, porque o terror escolhe as suas vítimas independentemente de ações ou pensamentos individuais" (ARENDT, 1989, p. 519-520).

${ }^{8}$ Disponível em: http://www.arqshoah.com.br/galeria_justos.aspx. Acesso 13/06/2011.
} 
Guimarães Rosa, na função de cônsul-adjunto, tampouco tinha, via de regra, autonomia para assinar os vistos expedidos pelo consulado. O documentário (Outro Sertão) procura detectar o papel exercido por ele nesse contexto através de uma análise detalhada da correspondência diplomática do período, do relado de historiadores e da comparação com dados de outras representações diplomáticas brasileiras na Alemanha. E, acima de tudo, através dos testemunhos dos sobreviventes ou de seus descendentes. Nas lembranças e no cotidiano dessas pessoas, o filme encontra não apenas indícios sobre a vida de Guimarães Rosa, mas revelações sobre a história da emigração para o Brasil naquele momento (JACOBSEN e VILELA, 2006, p. 4).

O testemunho de Israel Klabin corrobora com as teorias de Costa, Jacobsen e Vilela:

Fux: Os estudos mostram que a Aracy inseria os papéis para conseguir os vistos para os judeus fugirem da Alemanha. E ela é considerada um justo.

Klabin: Sim, estou sabendo dessa história. Tinha até um número de vistos que ela deu que eu não me lembro qual era.

Fux: A questão que gostaria de saber é se o Guimarães Rosa estava consciente disso.

Klabin: Absolutamente consciente. Ele era um filossemita. [...]

Fux: E o Senhor acha que durante essa passagem do Guimarães por Hamburgo, quando a Aracy estava fazendo isso com os vistos, você acha que ele... porque tem uma corrente de estudiosos que querem mostrar que o Guimarães era um justo.

Klabin: Ele era um justo. Era ele que dava os vistos.

Fux: Não. Ele não tinha autonomia para isso.

Klabin: Sim, mas ele conseguia. A Aracy não conseguiria fazer isso sozinha. Quem conseguia fazer isso era ele. Você já teve lá em Yad Vashem? Eu estive e vi lá a árvore em homenagem a ela. Mas ele merecia também (KLABIN, 2011a).

Na entrevista concedida a Günter Lorenz, realizada em janeiro de 1965, Rosa, perguntado sobre sua participação na emissão de vistos, não é muito claro nem muito preciso nas suas respostas, apesar de insinuar seu conhecimento e sua luta como um verdadeiro jagunço:

Lorenz: Gostaria de concluir que todos esses assuntos enumerados tiveram grande importância em sua vida: a diplomacia, os cavalos, as religiões, os idiomas. Você goza também de uma fama legendária: dizem que você domina muitos idiomas, e que aprendeu alguns deles apenas para poder ler um determinado autor em sua versão original. Sabe-se também que como diplomata e exercendo as funções de cônsul geral do Brasil em Hamburgo, você provocou Hitler fora das normas da diplomacia, e salvou a vida de muitos judeus...

Rosa: Tudo isso é verdade, mas não se esqueça de meus cavalos e de minhas vacas. As vacas e os cavalos são seres maravilhosos. Minha casa é um museu de quadros de vacas e cavalos. Quem lida com eles aprende muito para sua vida e a vida dos outros. Isto pode surpreendê-lo, mas sou meio vaqueiro, e como você também é algo parecido com isto, compreenderá certamente o que quero dizer. Quando alguém me narra algum acontecimento trágico, digo-lhe apenas isto: "Se olhares nos olhos de um cavalo, verás muito da tristeza do mundo!" Eu queria que o mundo fosse habitado apenas por vaqueiros. Então tudo andaria melhor (COUTINHO, 1983, p. 77). 
Nesse primeiro momento da entrevista, quando Lorenz toca no importante assunto de sua suposta batalha contra Hitler, Rosa apenas responde que tudo o que Ihe foi perguntado era verdade, mas não entra em detalhes. Já no segundo momento Rosa e Lorenz são mais categóricos:

Lorenz: Esta diferença não é resultado, digamos assim, de unidades de experiência
de diferentes graus? Atrás dessa definição também se oculta muito de política.
Rosa: E exatamente isso! A política é desumana, porque dá ao homem o mesmo
valor que uma vírgula em uma conta. Eu não sou um homem político, justamente
porque amo o homem. Deveríamos abolir a política. Lorenz: Foi isto que em Hamburgo levou você a se arriscar perigosamente, arrebatando judeus das mãos da Gestapo?

Rosa: Foi alguma coisa assim, mas havia também algo diferente: um diplomata é um sonhador e por isso pude exercer bem essa profissão. O diplomata acredita que pode remediar o que os políticos arruinaram. Por isso agi daquela forma e não de outra. E também por isso mesmo gosto muito de ser diplomata. E agora o que houve em Hamburgo é preciso acrescentar mais alguma coisa. Eu, o homem do sertão, não posso presenciar injustiças ${ }^{9}$. No sertão, num caso desses imediatamente a gente saca o revólver, e lá isso não era possível. Precisamente por isso idealizei um estratagema diplomático, e não foi assim tão perigoso. E agora me ocupo de problemas de limites de fronteiras e por isso vivo muito mais limitado,

Lorenz: Não estou muito convencido de que seus colegas, neste caso seus colegas diplomatas, aprovarão incondicionalmente esta definição.

Rosa: A maioria deles, que não são verdadeiros diplomatas mas apenas políticos frustrados, vai me considerar louco. Espero que você também não me considere assim. Mas eu jamais poderia ser político com toda essa constante charlatanice da realidade. O curioso no caso é que os políticos estão sempre falando de lógica, razão, realidade e outras coisas do gênero e ao mesmo tempo vão praticando os atos mais irracionais que se possam imaginar. Talvez eu seja um político, mas desses que só jogam xadrez, quando podem fazê-lo a favor do homem. Ao contrário dos 'legítimos' políticos, acredito no homem e lhe desejo um futuro. Sou escritor e penso em eternidades. O político pensa apenas em minutos. Eu penso na ressurreição do homem (COUTINHO, 1983, p. 78).

Segundo Heloísa Vilhena de Araújo em seu livro Guimarães Rosa: Diplomata, Rosa seria contrário ao totalitarismo nazista e esta seria sua luta. Uma luta diplomática e não política já que "nessas condições, a atividade de Guimarães Rosa no Consulado-Geral em Hamburgo, em favor dos judeus perseguidos, seria um exemplo, não de ação política pois ação política era o Nazismo, mas sim de uma ação diplomática" (ARAUJO, 1987, p. 36). Assim, mesmo sem apontar diretamente o que de fato fez Rosa em favor dos judeus, Vilhena de Araújo recorre à entrevista de Rosa a Lorenz e discorre sua argumentação com base na diplomacia, na justiça e numa ação contrária ao Nazismo:

O próprio Guimarães Rosa descreve este domínio avassalador do político na Alemanha nazista, em seu conto 'O Mau Humor de Wotan'. Neste conto, fica claro o totalitarismo, a tirania da política na vida da Alemanha, penetrando os rincões mais escondidos da vida da população. É a esse totalitarismo que ele se refere quando diz a Lorenz, que Ihe perguntara sobre sua atividade em Hamburgo em favor dos judeus perseguidos pelo Nazismo, 'eu, o homem do sertão, não posso presenciar injustiças'. A tirania do político é, para ele, injustiça (ARAUJO, 1987, p. 35-36)

\footnotetext{
${ }^{9}$ Também citado por Felipe Fortuna em "Guimarães Rosa, viajante".
} 
Infelizmente no livro Guimarães Rosa: diplomata, apesar dos anexos apresentarem algumas cartas de Rosa, não encontramos nenhuma outra referência a esse caso, apenas o citado nas passagens acima.

Já o texto de Felipe Fortuna "Guimarães Rosa, viajante" presente no livro $O$ Itamaraty na cultura brasileira, mostra e tenta demonstrar a efetiva participação e preocupação de Rosa com os judeus durante sua época de Hamburgo:

\begin{abstract}
É evidente que a atuação de Guimarães Rosa em Hamburgo, no período dificílimo de 1938 a 1942, não se reduz à rotina consular e à coleção de casos pitorescos. Ao contrário, durante sua passagem pelo Consulado, não apenas a sua capacidade de trabalho foi testada à exaustão, mas também o alto valor do seu humanismo. No ainda debatido tópico das diretrizes governamentais brasileiras sobre a emissão de vistos para judeus, Guimarães Rosa surge engrandecido por sua sensibilidade e sentido de dever moral, que em alguns momentos estiveram mais elevados do que algumas das instruções existentes, marcada pela ambiguidade e por visível laxismo. Um historiador com Jeffrey Lesser considera o Cônsul em Hamburgo 'an extremely concerned and helpful diplomat', que logrou sobrepor-se a uma sequencia de contradições existentes em alguns documentos sobre a política de imigração brasileira. [...] Lesser acerta ao informar que o diplomata costumava ajudar as vítimas judaicas e emitia mais vistos do que a cota estipulada em lei (FORTUNA, 2002, p. 372).
\end{abstract}

Nos "Diários de Guerra" de Rosa encontramos sutis passagens sobre esse acontecimento, como mostrado no estudo de Ana Luiza Martins Costa:

23.II.940 - [...] em Budweis, cidade do sul da Bohemia [...] os judeus só poderão andar de bonde nas plataformas. Primeira cidade a introduzir isso.

20-IX-941 - Ontem começou a obrigação do destinctivo na roupa dos judeus [ faz o desenho de duas estrelas-de-davi; numa delas, ao centro, está escrito "judeu"]. Hoje, à tarde, vi o primeiro [...]

22-X-941 - [...] judias chorando no Consulado, por terem recebido a ordem de evacuação de Hamburgo, para o dia 24. Horrível (COSTA, 2006, p. 17).

Existem, ainda, outros estudos acerca desses diários de Guimarães Rosa, como o ainda não publicado Diário de Guerra de Guimarães Rosa de Eneida Maria Souza, Georg Otte e Reinaldo Marques. Jaime Ginzburg, em sua pesquisa de pós-doutorado realizada na UFMG, trabalhou no Acervo dos Escritores Mineiros com os diários de Rosa e publicou o artigo "Notas sobre o 'Diário de Guerra de João Guimarães Rosa'". Nesse rigoroso estudo, Ginzburg mostra como as constantes ameaças de bombas, as sirenes e o medo perturbaram Rosa e como ele registrou detalhadamente esses acontecimentos. Algumas passagens são úteis para este estudo.

Na sua composição, o "diário alemão" de Guimarães Rosa engloba uma diversidade de registros e escritas: [...] registro de fatos ligados ao desenrolar da guerra; comentários de leitura de jornais, com críticas às medidas dos nazistas relativas aos judeus, etc. (MARQUES, 2009, p. 329).

Não há aqui como ou por que especular, se o autor tivesse estendido seu "Diário" mais longamente, por exemplo, até 1943, se não teria se convencido de que deveria tomar partido contra o nazismo. Em vez de entrar nesse campo especulativo arriscado, é melhor permanecer nos limites da delimitação do texto. 
Rosa não era simpatizante do autoritarismo alemão. Porém, um raciocínio político e ideológico esquemático poderia pressupor que, como implicação segura de não estar identificado com o nazismo, o escritor estaria comprometido com a causa de sua eliminação, através do apoio às forças organizadas em torno dos Estados Unidos. A leitura do 'Diário' não sugere nem um nacionalismo pró-americano, ou anglófilo, nem um comprometimento geral com um dos lados da guerra. De fato, o 'Diário de Guimarães Rosa' aponta para uma crítica da violência de um modo mais abrangente. Essa inclinação se articula com uma inconformidade com a violência da guerra que ultrapassa uma expectativa de propor um debate das eventuais justificações políticas para sua realização, e passa a uma posição avessa à necessidade de atos de violência, independentemente de definições de quaisquer justificativas (GINZBURG, 2010, p. 97).

Como já mostrado por Ana Luiza Martins Costa e reafirmado por Reinaldo Marques na passagem acima, Rosa sentia-se incomodado com o tratamento e com as medidas aplicadas aos judeus. Na argumentação de Ginzburg percebemos que Rosa ainda não tinha tomado uma posição política. Entretanto, o fato mais importante, é que nesses diários Rosa, homem do sertão, é avesso a qualquer ato de violência, independentemente de definições de quaisquer justificativas. Também, em uma carta de Rosa à Pedro Barbosa (20.05.1939), escreve: "Somos acossados de pedidos, rogos, prantos, ameaças, o diabo! Tenho visto e ouvido coisas absurdas, impossíveis. E... nem sempre a gente pode atender" ${ }^{10}$ (CAMPOS apud COSTA, 2006, p. 16).

No documentário Os nomes do Rosa, Haroldo Campos (também referenciado por Ana Luiza Martins Costa) fala sobre a atitude de Guimarães Rosa em prol dos refugiados judeus:

[...] ele começou a dizer uma coisa que me espantou muito, porque as pessoas diziam que Rosa era conservador, um embaixador do Itamaraty... Ele começou a me falar do fascismo: '- Você não sabe, mas o fascismo é o Demo. Porque eu sei, eu estive lá e eu sei que é o Demo. Eu tive que lidar com alemães para proteger refugiados judeus... e não dou mais detalhes'. E eu fiquei espantado, porque não sabia daquela história toda, e depois eu vim a conhecer o fato real, de depoimentos, e, de fato, ele teve um papel de grande bravura pessoal e de grande bravura ética - eu acho que ele era cônsul do Brasil em Hamburgo -, dando respaldo a judeus que queriam fugir da Alemanha nazista. O que é muito bonito do ponto de vista ético e desmente aquela imagem de um Rosa ausente, protocolar, ligado mais àquelas pompas de embaixador. $E$, de fato, ele era um homem de grande vivência humana (CAMPOS apud COSTA, 2006, p. 49).

Em "A imagem da Alemanha em Guimarães Rosa como retrato auto-irônico", Paulo Astor Soethe, conjecturando um teor testemunhal dos contos "O mau humor de Wotan", "A senhora dos segredos" e a "A velha" (como indica Jaime Guinzburg), sugere uma culpa de Rosa, dada a sua impossibilidade de atuar diretamente na emissão de vistos. O artigo começa mostrando a germanofilia e o profundo conhecimento do alemão que Rosa possuía. Soethe apresenta exemplos de neologismos presentes em Rosa com base em palavras e estruturas dessa língua. Inicialmente um admirador da cultura alemã, Rosa, de acordo com Georg Otte (2002), mostra um desencantamento progressivo em virtude da realidade política que encontrou na Alemanha durante sua estada (1938-1942). Segundo Soethe, esses contos do Ave, palavra, sugerem certa ironia e descaso com a cultura alemã devido a esse desencanto.

${ }^{10}$ Fato também descrito ficcionalmente em seu conto "A velha". 
A argumentação de Soethe, entretanto, caminha para outra constatação. Partindo da hipótese de que a obra de Rosa tem um teor testemunhal, principalmente nos contos "O mau humor de Wotan", "A senhora dos segredos" e a "A velha", o autor sugere um vazio referencial na afirmação que Rosa fez a Lorenz ("Eu, o homem do sertão, não posso presenciar injustiças"). Segundo Soethe, esses contos seriam uma referência autobiográfica e escreve: "em ambos ("A velha" e "A senhora dos segredos") o diplomata nega-se a prestar ajuda para a emigração de uma mulher alemã, apesar da situação ameaçadora em que ela se encontra" (SOETHE, 2005, p. 296). Mais a frente o autor discorda de outras fontes:

Guimarães Rosa, que mereceu diversas vezes elogio e consideração por seu engajamento em favor dos judeus (cf. ARAUJO, 1987, p. 17; entre outros), parece desvelar a ambivalência de suas atitudes com a máscara reveladora da ficção. A meu ver, pode-se entrever sob a dicção literária a confissão indireta das omissões cabíveis a um diplomata brasileiro na Alemanha. Amadurece assim a simpatia de Rosa pela cultura alemã, antes idealizada. Precisa abdicar da identificação ingênua com a terra de poetas e pensadores e, ao mesmo tempo, por via irônica, partilhar com ela a tarefa de luta e arrependimento diante dos crimes cometidos nos anos 30 e 40, não apenas sob o Estado nazista (SOETHE, 2005, p. 296-297).

Georg Otte, em "O 'Diário de Guerra' de Guimarães Rosa" encontra passagens que mostram o maniqueísmo vivenciado por Rosa em relação à cultura alemã.

Rosa não fecha os olhos ao nazismo e fica indignado diante da proibição que impede crianças judias o acesso a uma praia pública. $O$ choque entre passado com conotações positivas e o presente que coincide com uma das fases mais nefastas da história alemã certamente constitui mais um fator para o já mencionado distanciamento de Rosa diante dos acontecimentos concretos. Cabe ressalta que, em momento algum, Rosa manifesta qualquer simpatia, ou mesmo compreensão, pelo regime nazista, fato este que parece ser óbvio diante do notório humanismo do nosso autor, mas que não deixa de ser notável diante das simpatias que vários integrantes do Estado Novo cultivavam pelos países do eixo (OTTE, 2006, p. 35).

Jaime Guinzburg, em "Guimarães Rosa e o terror total", revisita o artigo de Soethe, esclarecendo alguns pontos. Sobre os contos, escreve:

Os contos permitem formular a hipótese de que Guimarães Rosa tenha, em sua trajetória como diplomata, enfrentado difíceis situações. A embaixada, como lugar de mediação entre Alemanha e Brasil, pode ser um espaço em que afloram tensões, conflitos ideológicos e problemas militares. Esse espaço deveria ser particularmente difícil se Rosa era contrário ao antissemitismo e, como sugere Soethe, preferia o pacifismo à violência nazista. Se encararmos os contos como dotados de teor testemunhal, então o foco de interesse da leitura não consiste na confirmação dos fatos biográficos como tais. $\mathrm{Na}$ combinação de elementos biográficos com elaboração ficcional, Rosa pode obter um alcance político e ético importante para sua produção (GUINZBURG, 2010, p. 23).

Assim, segundo Guinzburg, em seu texto ficcional, Rosa pôde mostrar a sua completa limitação para intervir e modificar tal situação.

A atitude do Brasil em relação à entrada dos judeus é controversa. $O$ estudo de Jeffrey Lesser mostra que "a conjuntura das relações do Brasil com as potências 
aliadas de um lado e a gama de interesses econômicos advinda de dentro do país de outro foi o que possibilitou a reformulação da imagem do judeu e a consequente entrada de contingentes imigratórios, apesar das pressões ideológicas nacionalistas e nativista em contrário. Segundo o autor, a imagem negativa do judeu foi reprocessada a partir das necessidades da política externa brasileira que visava aproximar-se dos EUA e da Inglaterra" (MILGRAM, 2007, p. 382). Já no estudo de Maria Luiza Tucci Carneiro "a expressão ideológica nacionalista-antissemita do Estado Novo foi o fator determinante na obstrução da entrada de judeus ao Brasil e a responsável pelo seu balanço negativo" (MILGRAM, 2007, p. 382).

Lesser, em dois momentos, e com base nos documentos do Itamaraty, ressalva a participação de Rosa na emissão de vistos a imigrantes: "O cônsul brasileiro em Hamburgo, o poeta João Guimarães Rosa que foi preso pelos nazistas quando o Brasil entrou na guerra ao lado dos Aliados, havia ajudado vítimas judias do nazismo no passado e era conhecido por ultrapassar sua quota de emissão de vistos de imigrantes" (LESSER, 1994, p. 269). Dessa forma, Rosa procurava agir dentro da lei com o intuito de ajudar os judeus. Uma ressalva: Rosa foi retido (e não efetivamente preso) em Baden-Baden durante quatro meses, já que em 1942, "com a ruptura das relações diplomáticas entre o Brasil e os países do Eixo, o corpo diplomático e outros funcionários brasileiros latino-americanos são internados num hotel em Baden-Baden [...] permanecem confinados num hotel com suas famílias e sofrem racionamento de comida e a proibição de sair à rua" (COSTA, 2006, p. 18).

Talvez o grande medo de Rosa fosse o de fazer concessões individuais para obtenção de vistos, como fazia Aracy (apesar de que quem salva uma vida salva um mundo inteiro). Lesser conjectura um possível plano ardiloso de Rosa para conseguir legalmente muitos vistos a católicos não-arianos (aqueles que eram considerados judeus pelos nazistas, devido a sua ascendência, mas que eram considerados católicos pelo Vaticano, dada a sua conversão). No capítulo 5 do livro $A$ questão judaica, é narrado um episódio envolvendo a concessão ou não de vistos a católicos não-arianos e as relações estabelecidas entre o governo de Getúlio Vargas e o Vaticano. O Vaticano queria salvar os de fé cristã, mesmo com ascendência judaica, já que esses, para os nazistas, eram judeus. Inúmeras negociações foram feitas, mas nenhum visto foi fornecido. Vargas queria se promover como humanista para ser visto com bons olhos pelos americanos, mas ao mesmo tempo não queria aceitar judeus no Brasil (dada a vigência da Lei 1.127). Já o Vaticano queria salvar aqueles que praticavam e seguiam a sua fé, mostrando assim sua 'benevolência'. Acerca do esquema Vaticano-Vargas, Rosa, de acordo com Lesser, diz que o "ignorava completamente":

O cônsul declarou estar chocado com o fato de os refugiados estarem solicitando vistos e comentou que eles 'dizem ter recebido autorização do governo brasileiro, em consideração especial ao Papa, para entrar em território nacional com vistos permanentes'. Guimarães Rosa era um diplomata extremamente preocupado e prestativo, mas, como praticamente todos os membros do regime Vargas, ele considerava os católicos não-arianos como racialmente e imutavelmente 'semitas de religião católica' ou 'católicos judeus'. O que surpreendeu particularmente o cônsul era que, entre os que se candidatavam a vistos para católicos não-arianos, havia um número considerável de católicos alemães do alto clero que estavam fugindo dos nazistas. Guimarães Rosa não era tolo, mesmo quando demonstrava 


\begin{abstract}
saber como se fingir de bobo. A despeito da alegação do diplomata, ele de fato sabia que haviam sido encaminhadas negociações para a concessão de três mil vistos para católicos não-arianos. Ao perguntar inocentemente a Aranha a respeito do plano, Guimarães Rosa anexou um a cópia de um telegrama do Cardeal Maglione para o Cardeal Faulhaber sobre os católicos não-arianos, que 'veio parar em minhas mãos por acaso'. Fingindo supor, em benefício próprio, que Aranha também desconhecia o plano (e sabendo que o ministro havia deixado de informar a ele e a outros diplomatas a esse respeito), Guimarães Rosa propôs que o CIC (Conselho de Imigração e Colonização) Ihe concedesse uma quota especial de mil visto, para que ele tratasse das solicitações novas e inesperadas dos refugiados católicos. Aparentemente, esse pedido ficou sem resposta (LESSER, 1995, p. 278-279).
\end{abstract}

Estaria Rosa planejando um grande esquema para conseguir mil vistos e fazer com eles o que desejasse? Rosa teria ou não participado efetivamente da emissão de vistos e com isso salvado vidas? Conjecturas e mistérios que nunca serão respondidos.

\title{
Considerações finais
}

Não devemos esquecer de lembrar. O mandamento judaico da memória, o Zakhor deve ser praticado, sobretudo para enaltecer os verdadeiros e revelados justos e para tentar narrar, mesmo os acontecimentos indizíveis. "A memória só existe ao lado do esquecimento: um complementa e alimenta o outro, um é o fundo sobre o qual o outro se inscreve" (SELIGMANN-SILVA, 2003, p. 53). Israel Klabin deu seu depoimento, seu testemunho (no sentido testis) em favor da memória de Rosa. O seu lembrar é a afirmação da sua vida e da sua existência. "Qualquer fato histórico mais intenso permite - e exige! - o registro testemunhal tanto no sentido jurídico como também no sentido de 'sobrevivente'"' (SELIGMANN-SILVA, 2003, p. 9). A Shoah tentou apagar a memória da História. Os lager foram instrumentos da eliminação física e memorial da existência de muitos. O testemunho de Israel Klabin e os dos sobreviventes da Shoah são inexatos e incompletos mas, como salientou Derrida: "o testemunho tem sempre parte com a possibilidade ao menos da fiç̧ão, do perjúrio e da mentira. Eliminada essa possibilidade, nenhum testemunho será possível e, de todo modo, não terá o sentido de testemunho" (DERRIDA, 1998, p. 28).

Aqui percebemos a falta de informação, ainda, acerca do período em que Rosa trabalhou na Embaixada Brasileira de Hamburgo. Os artigos, livros, documentários, entrevistas, diários e pesquisas discutidos apresentam uma certa circularidade, já que acabam citando e comentando as mesmas passagens sobre esse fato. Soethe e Otte mostraram a proximidade de Rosa com as Letras e a cultura germânica. Neste estudo, tento aproximar Rosa dos valores e da cultura judaica em virtude de sua convivência calorosa com a família Klabin acrescentado, assim, uma nova e importante informação em relação a esses estudos.

Este artigo teve, portanto, o intuito de agregar um pouco mais no mistério da participação de Rosa durante seu período em Hamburgo. Com base nos documentos históricos, relatos, livros e artigos confeccionou-se uma fundamentação teórica que foi corroborada com o inédito testemunho de Israel Klabin. Ainda restam muitas dúvidas, muitas questões, apesar de mais um passo ter sido dado para a lembrança positiva do homem do sertão. 


\section{Bibliografia}

ARAUJO, Heloísa Vilhena. Guimarães Rosa: Diplomata. Brasília: Fundação Alexandre Gusmão, 2007.

ARENDT, Hannah. Origens do totalitarismo. São Paulo: Companhia das Letras, 1989.

DELFINI, Mariana. Palavras de Guerra. In: Revista Bravo 126. São Paulo: Editora Abril, Fevereiro 2008. p. 29-39.

CARNEIRO, Maria Luiza Tucci (org.). O anti-semitismo nas américas. São Paulo: Edusp, 2007.

CARNEIRO, Maria Luiza Tucci. Metáforas de uma civilização. In: O anti-semitismo nas américas. São Paulo: Edusp, 2007.

O anti-semitismo na Era Vargas. São Paulo: Perspectiva, 2001.

COSTA, Ana Luiza Martins. Veredas de Viator. In: Cadernos de literatura brasileira. Rio de Janeiro: Instituto Moreira Salles, 2006. p. 10-58.

COUTINHO, Eduardo F. (org). Guimarães Rosa. Rio de Janeiro/Brasília: Civilização Brasileira/INL, 1983.

CORNELSEN, Elcio; BURNS, Tom. Literatura e guerra. Belo Horizonte: Ed. UFMG, 2010.

CRUZ, Natália dos Reis. O integralismo e a questão racial. A intolerância com princípio. Tese de doutorado. Niterói, UFF, 2004. Disponível em:

http://www.bdtd.ndc.uff.br/tde_arquivos/6/TDE-2008-02-12T131123Z-

1272/Publico/Tese_CRUZ_Natalia_dos_Reis.pdf. Acesso em 12/06/2011.

DERRIDA, Jacques. Demeure. Paris: Galilée, 1998.

FORTUNA, Felipe. Guimarães Rosa, viajante. In: SILVA, Alberto da Costa e (org.). $O$ Itamaraty na Cultura Brasileira. Rio de Janeiro: Francisco Alves, 2002.

JACOBSEN, Adriana; VILELA, Soraia. Outro sertão. In: Cadernos de literatura brasileira. Rio de Janeiro: Instituto Moreira Salles, 2006 (encarte).

JORNAL DA TARDE. 13 de Fevereiro de 1968. Disponível em:

http://blogs.estadao.com.br/arquivo/files/2011/03/1968.02.13.jpg. Acesso em $13 / 06 / 2011$.

GINZBURG, Jaime. Notas sobre o "Diário de Guerra de João Guimarães Rosa". In: Aletria 2 v.20. Maio-Agosto, 2010 p. 95-107.

Guimarães Rosa e o terror total. In: Elcio Cornelsen; Tom Burns. (Org.). Literatura e guerra. Belo Horizonte: Editora da UFMG, 2010, p. 17-27.

Joãozito: A infância de João Guimarães Rosa. São Paulo: Panda Books, 2006.

KLABIN, Israel. Poemata. Rio de Janeiro: Editora Bloch, 1950. 
Carta a Guimarães Rosa. Rio de Janeiro, 30 de Agosto de 1963.

Entrevista concedida a Jacques Fux. Rio de Janeiro, 30 de Maio de 2011a (45min).

A urgência do presente. Rio de Janeiro: Elsevier, 2011b.

MILGRAM, Avraham. O Itamaraty e os judeus. In: CARNEIRO, Maria Luiza Tucci (org.). O anti-semitismo nas américas. São Paulo: Edusp, 2007 (p. 379-410).

LESSER, Jeffrey. O Brasil e a questão judaica. Rio de Janeiro: Imago, 1995.

Semitismo em Negociação: O Brasil e a questão judaica (1930-1945). In: CARNEIRO, Maria Luiza Tucci (org.). O anti-semitismo nas américas. São Paulo: Edusp, 2007 (p. 271-290).

LORENZ, Günter. Diálogo com Guimarães Rosa. In: COUTINHO, Eduardo F. (org) Guimarães Rosa. Rio de Janeiro/Brasília: Civilização Brasileira/INI, 1983.

MARQUES, Reinaldo. Grafias de coisas, grafias de vida. In: MARQUES, Reinaldo; SOUZA, Eneida Maria. Modernidades alternativas na América Latina. Belo Horizonte: Editora UFMG, 2009. p. 327-350.

MIZRAHI, Rachel. Imigrantes judeus do oriente médio. São Paulo: Ateliê Editorial 2003.

OTTE, Georg. O "Diário Alemão" de João Guimarães Rosa - Relato de um projeto de pesquisa em andamento. In: DUARTE, Lélia Parrreira (org.). Veredas de Rosa II. Belo Horizonte: PUC Minas, 2002. p. 285-290.

. Os diários de guerra de Guimarães Rosa. Suplemento Literário. Belo Horizonte, Maio, 2006. p. 34-36.

PFEFFER, Renato Somberg. Vidas que sangram história: a comunidade judaica de Belo Horizonte. Belo Horizonte: Editora C/ Arte, 2003.

RICUPERO, Rubens. Confluências. In: ROSA, João Guimarães. Cadernos de literatura brasileira. Rio de Janeiro: Instituto Moreira Salles, 2006 (p. 66-75).

ROSA, João Guimarães. Carta a Israel Klabin. Paris, 4 de Junho 1949a.

Carta a Israel Klabin. Paris, 17 de Julho 1949b.

Ave, palavra. Rio de Janeiro: Livraria José Olympio Editora, 1978.

Cadernos de literatura brasileira. Rio de Janeiro: Instituto Moreira Salles,

2006.

Os nomes do Rosa. Documentário. 1997.

Estudos avançados 58. São Paulo: USP, 2006.

SCLIAR, Moacyr. Prefácio. In: GUIMARAES, Vicente. Joãozito: A infância de João Guimarães Rosa. São Paulo: Panda Books, 2006.

SELIGMANN-SILVA, Márcio. História Memória Literatura: o testemunho na era das catástrofes. Campinas: Editora Unicamp, 2003. 


\section{O local da diferença: ensaios sobre memória, arte, literatura e} tradução. São Paulo: Editora 34, 2005.

SILVA, Alberto da Costa e (org.). O Itamaraty na Cultura Brasileira. Rio de Janeiro: Francisco Alves, 2002.

SOETHE, Paulo Astor. A imagem da Alemanha em Guimarães Rosa como retrato auto-irônico. Scripta, Belo Horizonte, v.9, n.17, p. 287-301, 2005.

TESS, Eduardo de Carvalho. Entrevista a Claudio Camargo e Hugo Studart. "Uma heroína quase esquecida". ISTOÉ, 23 de Janeiro de 2008. Edição 1994. Disponível em: http://www.istoe.com.br/assuntos/semana/detalhe/477_UMA+HEROINA+QUASE+ESQ UECIDA ?pathImagens=\&path=\&actualArea=internalPage. Acesso em 13/06/2011.

\section{Title}

João Guimarães Rosa: a philo-semite? The Jewish issue, the letters and the testimony of Israel Klabin

\section{Abstract}

This article aims to show the relationship between João Guimarães Rosa and Israel Klabin's jewish family. From the correspondence between Rosa and Klabin and also from an interview granted to the author of this study, the philo-semitism of Rosa is demonstrated. Furthermore, based on documents, books and deep research, this article discusses the familiarity and proceedings of Rosa with regards to the issue of conceding visas to Jews during his time in the Brazilian Embassy in Hamburg.

\section{Keywords}

Rosa. Nazism. Philo-Semitism. Anti-Semitism. Testimony. 